\title{
9 \\ Australia: Maximising Discretion in an Untested Alliance
}

\author{
Brendan Sargeant
}

A central feature of Australia's participation in the Australia-US alliance has been Australia's support for US strategic capabilities. Australia provides support for US capabilities through joint facilities at Pine Gap and elsewhere and through arms control monitoring and treaty verification. ${ }^{1}$ Within this framework, Australia comes within the US policy of extended deterrence. This aspect of the Australia-US alliance has not featured prominently in the recent official discourse concerning the alliance, but this is changing due to the return of great power competition in the Indo-Pacific as the major strategic challenge facing Australia. Great power competition brings with it the risk of conflict. Understanding how crises might escalate, including escalation to a potential nuclear conflict, is a central concern for alliance management. This chapter gives a brief overview of Australia's alliance management in recent decades, including the role of deterrence in Australia's defence policy. It suggests some areas where traditional approaches to alliance management may not be fit for the emerging Indo-Pacific strategic environment.

1 Christopher Pyne, 'Ministerial Statements-Joint Facilities: Enhancing Australia’s Security and Prosperity-Statement by the Minister for Defence', Parliament of Australia, 20 February 2019, parlinfo.aph.gov.au/parlInfo/search/display/display.w3p;query=Id\%3A\%22chamber\%2Fhansardr\% 2Fe0e7b3e2-2c86-47b4-8de2-de9e8f0f224b\%2F0026\%22;src1=sm1. 


\section{Deterrence and the Alliance in Australian Strategic Policy}

Deterrence as an element of strategic policy is embodied in Australia's policy of self-reliance - the ability to defend Australia and its interests and be a security provider in the near region. This rests on an understanding of Australia's strategic geography, validated by historical experience. In this respect, self-reliance recognises that Australia will need to operate alone or with minimal assistance from its alliance partner against threats from within its own neighbourhood, especially Indonesia. ${ }^{2}$ The need for conventional deterrence capabilities has been a primary driver of the development of the Australian Defence Force structure, particularly through the acquisition of submarine and air strike capabilities.

Notwithstanding the different emphasis of defence white papers and other policy documents over many years, the idea of self-reliance and the capacity to defend Australia with minimal assistance remains an enduring feature of Australia's strategic policy. The 1987 Defence White Paper expressed strategic and defence policy as one of self-reliance within a framework of alliances and agreements. ${ }^{3}$ This latter qualification (of alliances and agreements) speaks to the reality that Australia has always sought to engage with larger global strategic systems and to participate in the development and maintenance of regional and global strategic architectures and institutions.

The Australia-US alliance sits at the centre of Australian strategic policy and contributes to Australian deterrence because it ties Australia in close relationship to the US. Like all alliances, it brings obligations, the most important being the obligation to consult in the event of a crisis. The 1951 Australia, New Zealand, United States Security Treaty states:

Each party recognises that an armed attack in the Pacific area on any of the parties would be dangerous to its own peace and safety and declares that it would act to meet the common danger in accordance with its constitutional processes. ${ }^{4}$

2 Stephan Frühling, 'Australian Defence Policy and the Concept of Self-Reliance', Australian Journal of International Affairs 68(5), 2014, 531-47, doi.org/10.1080/10357718.2014.899310.

3 Department of Defence, 1987 Defence White Paper (Canberra: Australian Government Publishing Service, 1987).

4 Department of External Affairs, The ANZUS Treaty 1951 (Canberra: Australian Government Publishing Service, 1952). 
Within the broad alliance framework underpinned by the treaty, Australia and the US have developed a robust culture of collaboration across the full spectrum of defence activities. For Australia, participation in the alliance brings incommensurable benefits, and the cost of non-participation is potentially great. This applies particularly to capability, where interdependency has increased substantially in recent decades. ${ }^{5}$ By providing access to capabilities and intelligence otherwise not available, the alliance contributes to Australia's capacity for self-reliant conventional deterrence.

\section{Extended Deterrence in Australian Strategic Policy}

The salience of extended deterrence in Australian strategic policy has varied in response to strategic circumstances. During the Cold War, Australia's strategic contribution was to participate in US systems designed to advance Western strategic interests in South-East Asia, including the Southeast Asia Treaty Organization, and its commitment to the Vietnam War. Extended deterrence was one element of the broader alliance policy architecture, but Australia was more a partner in extending it to regional partners in South-East Asia than a recipient. As Stephan Frühling has discussed, 'extended deterrence was never truly effected in Australia's case and as a result, Australia was spared most of the difficult political and military dilemmas inherent in receiving extended deterrence'. ${ }^{6}$ In this respect, its policy significance has been political rather than practical.

In the 2000s, the East Timor crisis and the 9/11 attack by Al-Qaeda focused Australian Defence Force activity on a series of operational commitments. This included the stabilisation of East Timor and involvement in the response to other regional challenges, including to crises in Bougainville and Solomon Islands. More important in terms of the alliance was participation as a coalition partner with the US in Afghanistan and Iraq as part of the response to $9 / 11$ and the challenge of global terrorism. This shifted the emphasis of the alliance towards

5 James Goldrick, 'Interoperability', in Australia's American Alliance, ed. Peter Dean, Stephan Frühling and Brendan Taylor (Melbourne: Melbourne University Press, 2016), 163-78.

6 Stephan Frühling, 'The Fuzzy Limits of Self-Reliance: US Extended Deterrence and Australian Strategic Policy', Australian Journal of International Affairs 67(1), 2013, 18-34, doi.org/10.1080/103 57718.2013.748273. 
activity where Australia's primary role was directed to providing political and operational support for the US. The strategic environment did not highlight potential confrontation between great powers that could escalate to a nuclear confrontation as a first-order issue.

In 2017, however, during one of the periodic crises that characterise North Korea's relations with its neighbours, the US and other countries in the Indo-Pacific, North Korea raised the prospect of using nuclear weapons. It issued direct nuclear threats against Australia in April and October 2017. ${ }^{7}$ These threats were dealt with in the context of crisis management at the time. ${ }^{8}$ However, there were longer-term implications for the US-Australia alliance. The first was that there was little that Australia could do unilaterally. Policy responses, of which there were limited options, could only be undertaken in the context of crisis management by the US. In this respect, Australia was unprepared. ${ }^{9}$ Second, the policy of extended deterrence returned to the public discourse. During that period, there was a lively discussion among commentators about extended deterrence and its continuing relevance. The foreign minister at the time, Julie Bishop, in several interviews, referred to extended deterrence as one element of Australia's strategic response. ${ }^{10}$ Third, the crisis signalled that the Indo-Pacific was an arena where a nuclear crisis could emerge quickly, potentially escalate and Australian strategic interests were engaged.

The question that arises from this concerns how extended deterrence might operate in an environment that continues to have features created during the Cold War along with those that have emerged more recently. Specifically, how relevant is it to contingencies that might involve China?

7 'North Korea Threatens Australia with Disaster if it Continues to Support US Stance on Pyongyang', $A B C$ News, 15 October 2017, www.abc.net.au/news/2017-10-15/north-korea-warns-australia-facedisaster-continues-support-us/9051156; 'North Korea Threatens Australia with Nuclear Strike over US Allegiance', news.com.au, 24 April 2017, www.news.com.au/world/north-korea-threatens-australiawith-nuclear-strike-over-us-allegiance/news-story/2cf2f736bf4e530e59f99e8d04d913b3.

8 Stephen Dziedzic, 'North Korea Threatens Australia with "Disaster", Julie Bishop Says Nation Is Not a Primary Target', $A B C$ News, 15 October 2017, www.abc.net.au/news/2017-10-15/juliebishop-speaks-on-north-korea/9051912.

9 Andrew O'Neil, Brendan Taylor and William T. Tow, 'Australia and the Korean Crisis: Confronting the Limits of Influence?', Centre of Gravity 40, 2018.

10 'ABC 7.30 Report, Interview with Leigh Sales', Minister for Foreign Affairs The Hon Julie Bishop MP, 29 August 2017, www.foreignminister.gov.au/minister/julie-bishop/transcript-eoe/abc730-report-interview-leigh-sales; 'ABC AM, Interview with Sabra Lane', Minister for Foreign Affairs The Hon Julie Bishop MP, 30 August 2017, www.foreignminister.gov.au/minister/julie-bishop/ transcript-eoe/abc-am-interview-sabra-lane- 2 . 
In this respect, the effect of the North Korean crisis was to highlight the complexity of the nuclear dimension of the Indo-Pacific strategic environment and the immaturity of existing strategic architectures.

\section{Managing the Alliance}

Contemporary Australian strategic policy thus faces two entirely different challenges. The first challenge is how Australia might participate effectively in a global alliance system managed by the US and underpinned by US nuclear capability. This challenge is made more complex by changes occurring across the Indo-Pacific combined with the acquisition of nuclear capabilities (or the potential to acquire them quickly) by Indo-Pacific countries. The second challenge is developing effective conventional deterrence in the context of major power threats that might emerge in Australia's near region.

The 2020 Defence Strategic Update recognises that deterrence capabilities are needed to provide Australia with the capacity to resist challenges by major powers in Australia's neighbourhood. ${ }^{11}$ The Strategic Update also emphasises developing infrastructure and levels of interoperability with the US that strengthen Australia's capacity to operate with the US in the broader Indo-Pacific. ${ }^{12}$ This is not necessarily a contradiction, but it is a challenge to policy and operational cultures because crisis preparation needs to develop the capacity to manage across the potential spectrum of future possibilities. A crisis in the near region may require a very different response and capability to one that might occur in North Asia.

Australia's management of the alliance since the Vietnam War through to the beginning of the Trump era responded to a strategic environment that was relatively stable and, in terms of potential crises, relatively low risk. The superpowers had protocols and modes of communication to ensure effective crisis management. There were many local crises, but the larger pattern of forces that structured the global order was remarkably stable, providing a secure strategic environment for Australia. Strategic assessments at the time were confident that there would be at least a decade-long warning before a major military threat to Australian security would

11 Department of Defence, 2020 Defence Strategic Update, www1.defence.gov.au/sites/default/ files/2020-11/2020_Defence_Strategic_Update.pdf, 33.

12 Ibid., 26. 
emerge. ${ }^{13}$ This was built on the assumption that the struggle between the US and the Soviet Union, though existential and all-encompassing in its range and intensity, was a force for stability. Australia's strategic security was underpinned by US extended deterrence across the region, which was explicit in the case of US alliances in North-East Asia and more implicit in the case of Australia itself.

In this context, Australia has managed its alliance relationship by establishing processes that enable it to maximise its discretionary decision-making capacity. ${ }^{14}$ Australia has developed a set of arrangements and protocols that enable it to condition participation, particularly in relation to decisions that might involve Australia in US strategic or operational activities. Perhaps the most prominent example is the 'full knowledge and concurrence' arrangements at Pine Gap and other joint facilities. ${ }^{15}$ What this means in practice is that they are established as joint facilities, not US bases, with integrated workforce and management arrangements, and where activities that occur or go through those facilities do so with the full knowledge and concurrence of the Australian Government. Other examples include the management of US aircraft and ship visits and the framework governing the rotational deployments of the US Marines to Darwin initiated under the Gillard government. ${ }^{16}$

Australian policy, in its practical application, has been operationally focused, concerned with managing participation in the context of a domestic environment where elements of the alliance are contested, and in an international environment that was relatively stable and where major crises were managed at the superpower level. This has enabled Australia to gain the deterrence benefits of the alliance while minimising the cost in terms of commitments that might intrude on Australia's capacity to exercise independent decision-making in its national interest.

13 Department of Defence, 1976 Defence White Paper (Canberra: Defence Publishing Service, 1976); Department of Defence, 1987 Defence White Paper; Department of Defence, 1991 Force Structure Review (Canberra: Defence Publishing Services, 1991).

14 Kim Beazley, 'Sovereignty and the US Alliance', in Australia's American Alliance, ed. Peter Dean, Stephan Frühling and Brendan Taylor (Melbourne: Melbourne University Press, 2016), 203-23.

15 Stephen Smith, 'Full Knowledge and Concurrence', Parliament of Australia, 26 June 2013, parlinfo.aph.gov.au/parlInfo/search/display/display.w3p;query=Id\%3A\%22chamber\%2Fhansardr\% 2F4d60a662-a538-4e48-b2d8-9a97b8276c77\%2F0016\%22.

16 Department of Foreign Affairs and Trade, The Force Posture Agreement between the Government of Australia and the Government of the United States of America (Canberra: Department of Foreign Affairs and Trade, 2014). 


\section{Understanding Mutual Expectations within the Alliance}

The 2020 Defence Strategic Update signalled that Australian policy could no longer rely on past assumptions about the extent of the warning time decision-makers might have before and during a crisis. ${ }^{17}$ This has many consequences and profound implications for defence planning. It also has implications for alliance management.

The increasingly adversarial relationship between the US and China means that the possibility of an incident occurring between American and Chinese military forces has increased. This is overlaid on the Indo-Pacific strategic environment, which has several potential flashpoints. Each of these flashpoints, through either intention or accident, has the potential to escalate to a major confrontation. In some circumstances, particularly with Taiwan, the potential for escalation to a nuclear confrontation exists. Putting to one side the political context, the practical reality for Australia is that very high levels of interdependence with US strategic and operational systems mean that, in some contingencies, Australian participation would reduce the burden on US capabilities. A decision not to participate would have major implications for the alliance.

A major crisis, such as a Taiwan contingency, will therefore confront Australia with real dilemmas. First, due to the degree of integration with US forces across the Indo-Pacific, and given the infrastructure that Australia would be contributing to the capacity of those forces to operate, Australia will have a degree of involvement regardless of decisions that it may wish to make. While it is likely to have some discretion over the degree of involvement, that very much depends on circumstances at the time. Second, Australia will not be in control of the process of escalation. This means that policy will be directed not only at managing participation in response to the crisis but also at Australia's relationship with its alliance partner. Third, given the interdependent economic, trading and cultural linkages that Australia has across the Indo-Pacific, including with potentially adversarial countries, a major crisis in which Australia does not control escalation is likely to be a major disruptor to existing and future patterns of activity, and what emerges may not necessarily be in Australia's interests.

17 Department of Defence, 2020 Defence Strategic Update, 14. 
In the current environment, particularly in the context of the potential crises that could occur, the central alliance question concerns each party's expectations in a crisis and how these expectations would be expressed in operational arrangements. In this respect, Australian policy, at least as declared publicly, is ambiguous. Intelligence arrangements continue broadly within frameworks established decades ago. Operational activity in the form of exercises, training and participation in US fleet activities continues. Infrastructure is being developed in Australia that will strengthen the capacity of the US to operate from Australia. However, agreements and arrangements governing US activities in Australia are carefully designed to place limits on the ability of the US to act without close consultation and the implied consent of the Australian Government. ${ }^{18}$ This adds up to strategic imperatives that seem to be suggesting greater degrees of integration but policy frameworks that also seek to maximise discretion in Australian Government decision-making. The question is whether this ambiguity would withstand the pressure of a major strategic crisis such as a Taiwan contingency.

\section{Understanding Time as a Diminishing Strategic Resource}

The most important resource in crisis management is time. One of the features of the contemporary strategic environment is that time is an increasingly diminishing resource, as a result of both technology (and particularly of cyber technologies) and the increased proximity of countries in contested domains. In this respect, Australian alliance management processes, including the deterrent posture they imply and the capabilities that it might develop, need to create more time for positioning and decision-making, both strategically and operationally.

Effective deterrence creates time and secure spaces. The 2020 Defence Strategic Update has signalled a focus on deterrence both as policy and in prospective capability development. However, in the context of the alliance, a different type of discussion also needs to occur. This involves

18 For example: Department of Foreign Affairs and Trade, The Force Posture Agreement between the Government of Australia and the Government of the United States of America (Canberra: Department of Foreign Affairs and Trade, 2014); 'Agreement with the Government of the United States of America Relating to the Establishment of a Joint Defence Space Research Facility [Pine Gap NT]', Australian Treaties, 9 December 1966, www.austlii.edu.au/au/other/dfat/treaties/1966/17.html. 
coming to an understanding and negotiation of mutual expectations in relation to future crisis management and response. The results of this need to be approved by government and translated into operational protocols. What is Australia prepared to do and what are its limits? There is no absolute answer to this question, but it needs to be discussed and some understandings reached. This is particularly important from an Australian perspective because crisis management may largely be the management of alliance partner expectations. This suggests that the alliance planning infrastructure needs to be formalised to a greater degree than it is at the moment. This has both an operational and a political dimension.

Finally, in a crisis, ministers through the National Security Committee of Cabinet chaired by the prime minister will be the ones responsible for the overall management of the response and the key decision-making. As part of the development of a stronger alliance planning infrastructure, the role of ministers must be central. One implication of this is that ministers will also need to take a much stronger interest and involvement in planning and managing the operational environment, particularly in terms of potential contingencies and to understand their role in shaping operational responses within a broader national interest and alliance framework.

The 2020 Defence Strategic Update signals a policy shift in response to change in Australia's strategic environment. The rise of China and its increasingly adversarial stance in the region, including in relation to the US, are driving other large forces for change. The Indo-Pacific has become more crowded, more contested, and regional decision-making institutions have become less capable of establishing agreement on how the strategic order should be managed in the future. ${ }^{19}$

In a crisis (and in crisis preparation), the US-being in control of escalation management-will want certainty and the capacity to plan and act on agreed assumptions. The imperative for the smaller partner is to create space that enables them to act in their own interests, even when it may be against the interests of the major partner. As noted above, Australian alliance management has sought to maximise discretionary space while at the same time implying commitment in a future crisis. In

19 Department of Defence, 2020 Defence Strategic Update, 6. 
recent decades, particularly in relation to participation in Afghanistan and Iraq, Australian policy has been to maximise the value of participation both in the context of the particular operations and more broadly in the context of the alliance, while minimising operational and strategic risk. The question now is whether traditional approaches to alliance management are sufficient in the context of a potential nuclear crisis in the Indo-Pacific.

We can consider, as an example, a crisis that has the potential to escalate to a nuclear confrontation. Such a crisis would be managed by the US. Australia will have equities, but the interests of the US could constrain the capacity to pursue them as it manages the crisis. Extended deterrence functions as a kind of guarantee of security from nuclear attack, yet in a major crisis, it is not certain how such a guarantee would be understood and implemented in practice. In this respect, crisis management should not rest on the assumption that Australia's strategic interests are so intertwined with those of the US that the US would, in its response, recognise and act in Australia's interests. This assumption has not been tested and assumes a convergence of strategic interests that in some circumstances may not exist. 
This text is taken from Alliances, Nuclear Weapons and Escalation: Managing Deterrence in the 21st Century, edited by Stephan Frühling and Andrew O'Neil, published 2021 by ANU Press, The Australian National University, Canberra, Australia.

doi.org/10.22459/ANWE.2021.09 